\title{
Elevated growth temperature decreases levels of the PEX5 peroxisome-targeting signal receptor and ameliorates defects of Arabidopsis mutants with an impaired PEX4 ubiquitin-conjugating enzyme
}

Yun-Ting Kao and Bonnie Bartel

\begin{abstract}
Background: Peroxisomes house critical metabolic reactions. For example, fatty acid $\beta$-oxidation enzymes, which are essential during early seedling development, are peroxisomal. Peroxins (PEX proteins) are needed to bring proteins into peroxisomes. Most matrix proteins are delivered to peroxisomes by PEX5, a receptor that forms transient pores to escort proteins across the peroxisomal membrane. After cargo delivery, a peroxisome-tethered ubiquitin-conjugating enzyme (PEX4) and peroxisomal ubiquitin-protein ligases mono- or polyubiquitinate PEX5 for recycling back to the cytosol or for degradation, respectively. Arabidopsis pex mutants $\beta$-oxidize fatty acids inefficiently and therefore fail to germinate or grow less vigorously. These defects can be partially alleviated by providing a fixed carbon source, such as sucrose, in the growth medium. Despite extensive characterization of peroxisome biogenesis in Arabidopsis grown in non-challenged conditions, the effects of environmental stressors on peroxisome function and pex mutant dysfunction are largely unexplored.

Results: We surveyed the impact of growth temperature on a panel of pex mutants and found that elevated temperature ameliorated dependence on external sucrose and reduced PEX5 levels in the pex4-1 mutant. Conversely, growth at low temperature exacerbated pex4-1 physiological defects and increased PEX5 levels. Overexpressing PEX5 also worsened pex4-1 defects, implying that PEX5 lingering on the peroxisomal membrane when recycling is impaired impedes peroxisome function. Growth at elevated temperature did not reduce the fraction of membrane-associated PEX5 in pex4-1, suggesting that elevated temperature did not restore PEX4 enzymatic function in the mutant. Moreover, preventing autophagy in pex4-1 did not restore PEX5 levels at high temperature. In contrast, MG132 treatment increased PEX5 levels, implicating the proteasome in degrading PEX5, especially at high temperature.

Conclusions: We conclude that growth at elevated temperature increases proteasomal degradation of PEX5 to reduce overall PEX5 levels and ameliorate pex4-1 physiological defects. Our results support the hypothesis that efficient retrotranslocation of PEX5 after cargo delivery is needed not only to make PEX5 available for further rounds of cargo delivery, but also to prevent the peroxisome dysfunction that results from PEX5 lingering in the peroxisomal membrane.
\end{abstract}

\footnotetext{
* Correspondence: bartel@rice.edu

Biochemistry and Cell Biology Program, Department of BioSciences, Rice University, Houston, TX, USA
}

\section{() Biomed Central}

(C) 2015 Kao and Bartel. Open Access This article is distributed under the terms of the Creative Commons Attribution 4.0 International License (http://creativecommons.org/licenses/by/4.0/), which permits unrestricted use, distribution, and reproduction in any medium, provided you give appropriate credit to the original author(s) and the source, provide a link to the Creative Commons license, and indicate if changes were made. The Creative Commons Public Domain Dedication waiver (http://creativecommons.org/publicdomain/zero/1.0/) applies to the data made available in this article, unless otherwise stated. 


\section{Background}

Peroxisomes house important metabolic reactions including $\beta$-oxidation. Oilseed plants, like Arabidopsis thaliana, $\beta$-oxidize fatty acids to provide energy for early seedling development before photosynthesis is established [1]. Because this $\beta$-oxidation is peroxisomal, dependence on an external source of fixed carbon, such as sucrose, during germination is a hallmark of peroxisome-defective mutants $[2,3]$.

Peroxisomes can derive from the endoplasmic reticulum and proliferate by division [4]. Morphology and numbers of peroxisomes can vary depending on the cell type, developmental stage, or environmental conditions [5, 6]. Peroxins (PEX proteins) function in peroxisome biogenesis and/ or matrix protein import $[4,7]$. Fully folded or oligomerized proteins can be post-translationally imported into the peroxisomal matrix by the peroxisomal import machinery [8]. PEX5 recognizes and delivers proteins carrying peroxisome targeting signal type 1 (PTS1), often a C-terminal tripeptide (e.g., SKL) [9]. The receptor-cargo complexes translocate cargo with the assistance of docking peroxins (PEX13 and PEX14); this importomer forms transient pores on the peroxisomal membrane to deliver cargo into the peroxisome matrix $[10,11]$.

After cargo delivery, PEX5 is recycled from the membrane back to the cytosol with the assistance of a peroxisome-tethered ubiquitin-conjugating enzyme (PEX4; tethered by PEX22) [12, 13] and RING-finger peroxins (PEX2, PEX10, PEX12) [14, 15]. In yeast, PEX4 and PEX12 monoubiquitinate PEX5 for recycling and further rounds of cargo delivery whereas UBC4 and PEX2 polyubiquitinate PEX5, which targets PEX5 for proteasomal degradation [16]. Ubiquitinated PEX5 is recognized and removed from the peroxisomal membrane by a complex of the PEX1 and PEX6 ATPases [17-19] and PEX26, which recruits the PEX1-PEX6 heterohexamer to the peroxisome [19-21].

Although Caenorhabditis elegans and Drosophila melanogaster direct essentially all matrix proteins to peroxisomes via the PEX5-PTS1 system [22-24], peroxisomes in various yeasts, plants, and mammals also can import proteins bearing N-terminal PTS2 nonapeptides (R[L/I/ $\left.\mathrm{Q}] \mathrm{X}_{5} \mathrm{HL}\right)$. PTS2 proteins are recognized and imported by PEX7 $[25,26]$. PEX5 and PEX7 are interdependent in plants $[25,27,28]$ and mutually enhance cargo-receptor interactions in mammals [29]. In plants, the protease DEG15 cleaves the N-terminal PTS2 region after delivery to the peroxisome matrix $[30,31]$. In mammals, damaged PEX7 can be ubiquitinated and degraded by the proteasome [32], but the mechanism by which undamaged PEX7 is recycled remains unclear.

Ubiquitin modification can target PEX5 for recycling or degradation [16]. Moreover, accumulating evidence suggests that balancing PEX5 targeting and retrotranslocation is important for normal peroxisome function $[14,33]$.
In this study, we demonstrate that elevated growth temperature reduces PEX5 levels in mutants defective in PEX5 recycling. We implicate proteasomal degradation rather than autophagy in this decrease. We hypothesize that reducing overall PEX5 levels relieves the detrimental effects of membrane-associated PEX5 in pex4-1 and ameliorates the associated physiological defects.

\section{Results}

\section{Growth at elevated temperature ameliorates the} peroxisomal defects of pex4-1

Peroxisomal fatty acid $\beta$-oxidation provides fixed carbon and energy to germinating Arabidopsis seedlings [1]. Peroxisomal mutants that inefficiently perform $\beta$-oxidation fail to germinate or grow less vigorously $[2,3]$. These defects can be partially reversed by supplementing the growth medium with a fixed carbon source, such as sucrose, which bypasses the need for $\beta$-oxidation. As a result, peroxisomal mutants have shorter hypocotyls or do not germinate without sucrose when grown at normal temperature $\left(22^{\circ} \mathrm{C}\right)$ (Additional file $1 \mathrm{~A}$ ).

To examine the effect of temperature on mutants with impaired peroxisome function, we surveyed peroxisomedefective mutants for sucrose dependence at normal $\left(22{ }^{\circ} \mathrm{C}\right)$ and elevated $\left(28{ }^{\circ} \mathrm{C}\right)$ growth temperatures. We tested mutants defective in matrix protein receptors (pex5-1, pex7-2) [3, 27], receptor docking (pex13-4, pex14-1) [34, 35], and receptor recycling (pex4-1, pex21 , pex10-2, pex6-1) $[13,14,17]$. Growth at $28{ }^{\circ} \mathrm{C}$ increased dark-grown hypocotyl lengths (Additional file 1A) but did not markedly alter sucrose dependence in wild type or most peroxisome-defective mutants tested (Fig. 1a, Additional file 1A). Interestingly, we found that high temperature ameliorated the sucrose dependence of dark-grown pex4-1 seedlings (Fig. 1a). At $22{ }^{\circ} \mathrm{C}$, pex4-1 hypocotyls were shorter without sucrose supplementation; however, at $28{ }^{\circ} \mathrm{C}$, pex4-1 hypocotyls were similarly long with or without sucrose (Additional file 1A). This restoration of sucrose independence by growth at high temperature was specific to pex4-1; the sucrose dependence of pex5-1, pex7-2, pex14-1, pex2-1 and pex10-2 was unchanged or very slightly exacerbated at high temperature, and pex13-4 did not germinate without sucrose at either temperature (Fig. 1a). We therefore focused on the pex4-1 mutant to elucidate the molecular changes in peroxisome function that accompany growth at high temperature.

In addition to fatty acids, indole-3-butyric acid (IBA) is $\beta$-oxidized in peroxisomes to indole-3-acetic acid (IAA), which inhibits cell elongation [3, 36, 37]. Similarly, the synthetic auxin precursor 2,4-dichlorophenoxybutyric acid (2,4-DB) is $\beta$-oxidized in peroxisomes to 2,4-dichlorophenoxyacetic acid (2,4-D) [2]. Consequently, wild-type hypocotyls are short following growth on IBA or 2,4-DB 


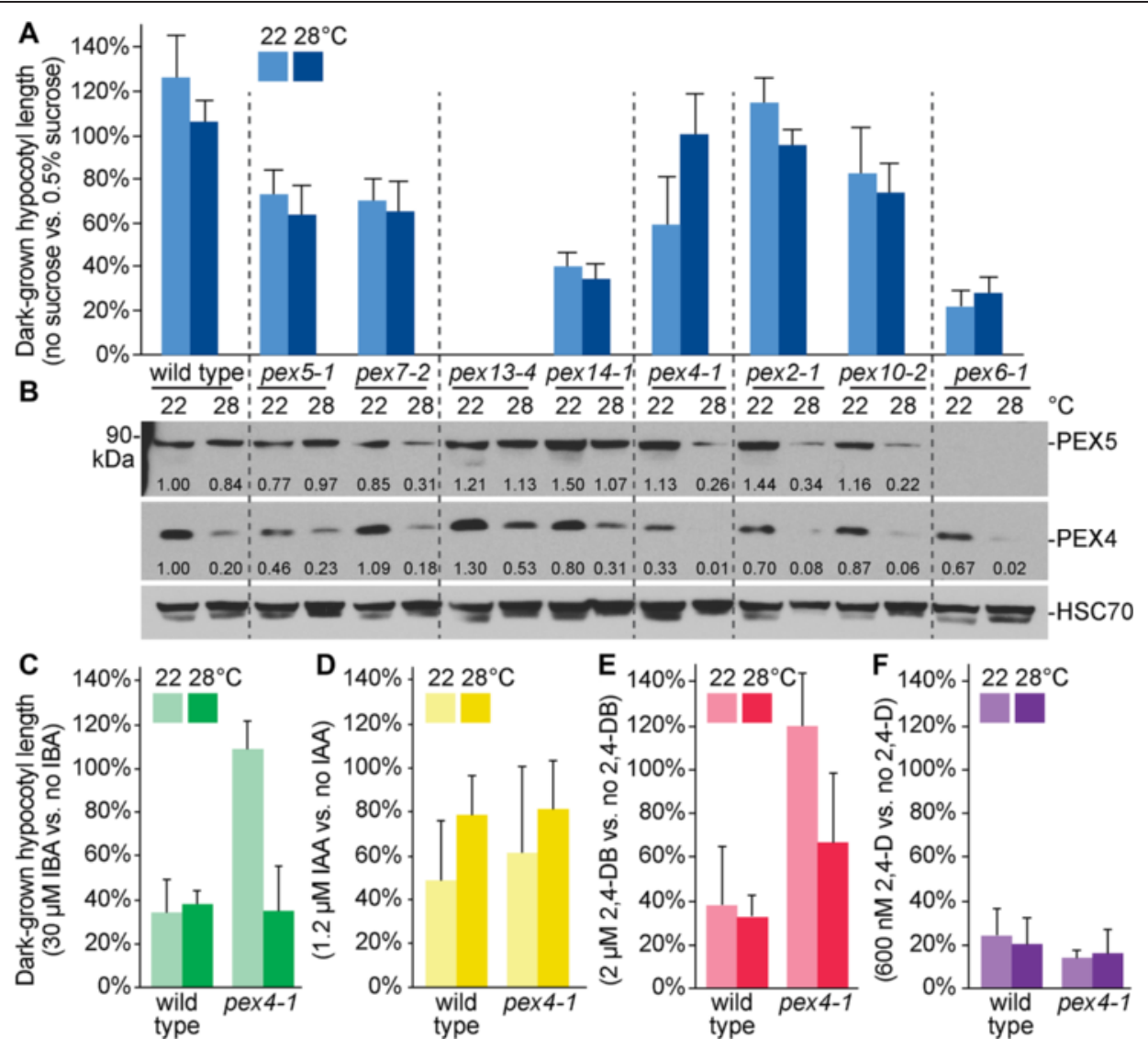

Fig. 1 High temperature ameliorates physiological defects and reduces PEX5 levels of pex4-1. Physiological consequences of growth temperature on pex mutants. Seedlings were grown in the dark at 22 or $28{ }^{\circ} \mathrm{C}$ with or without $0.5 \%$ sucrose (a), or on media containing $0.5 \%$ sucrose with or without $30 \mu \mathrm{M}$ IBA (c), $1.2 \mu \mathrm{M}$ IAA (d), $2 \mu \mathrm{M}$ 2,4-DB (e), or 600 nM 2,4-D (f). Dark-grown hypocotyl lengths were normalized to the corresponding mean of $0.5 \%$ sucrose treatment. Means of normalized dark-grown hypocotyl lengths and standard deviations of the means are shown $(n \geq 17$ for panel A and $n \geq 12$ for panels C-F). b Protein extracts of dark-grown seedlings from $0.5 \%$ sucrose-supplemented plant nutrient media in panel (a) were processed for immunoblotting. The membrane was serially probed with indicated antibodies. HSC70 was used to monitor protein loading. The positions of molecular mass markers (in $\mathrm{kDa}$ ) are indicated on the left. Band intensities were quantified using ImageJ; levels of PEX5 or PEX4 were normalized to the corresponding HSC70 band prior to normalizing to the $22^{\circ} \mathrm{C}$ wild-type band to give the listed numbers

whereas peroxisomal mutants often have longer hypocotyls [38] (Additional file 1A, B). Like sucrose dependence (Fig. 1a), we found that growth at high temperature partially restored IBA (Fig. 1c) and 2,4-DB (Fig. 1e) responsiveness to the pex4-1 mutant. To determine whether this restored IBA responsiveness stemmed from improved peroxisome function or generally increased responsiveness to auxin, we tested the response of pex4-1 to IAA and 2,4$\mathrm{D}$, which do not require peroxisomal chain shortening for biological activity. We found that pex4-1 responded like wild type to both IAA (Fig. 1d) and 2,4-D (Fig. 1f) at both normal and elevated growth temperatures. We concluded that growth at elevated temperature improves peroxisomerelated physiology in the pex4-1 mutant.

The Arabidopsis pex4-1 mutation alters a conserved proline residue and impairs PEX4 function [13], but the impact of this mutation on PEX4 levels has not been reported. We developed an antibody to Arabidopsis PEX4
(Additional file 2) and examined PEX4 levels in our various mutants following growth at normal or elevated temperatures. We detected PEX4 in all of the mutants grown at $22{ }^{\circ} \mathrm{C}$ and found PEX4 levels were generally reduced following growth at high temperature (Fig. 1b). In the pex4-1 mutant grown at $22{ }^{\circ} \mathrm{C}$, pex4-1 protein levels were reduced compared to wild type (Fig. 1b), suggesting that the Pro123Leu mutation destabilizes the pex4-1 protein. pex4-1 levels were further reduced in pex4-1 grown at $28{ }^{\circ} \mathrm{C}$ (Fig. 1b), indicating that high temperature did not ameliorate pex4-1 physiological defects by restoring pex4-1 protein levels back to wild-type PEX4 levels.

In yeast, the PEX5 PTS1 receptor is retrotranslocated from the peroxisomal membrane by the PEX1-PEX6 ATPase complex following ubiquitination by the PEX2PEX10-PEX12 ubiquitin-protein ligase complex assisted by the PEX4 ubiquitin-conjugating enzyme [16, 39]. In Arabidopsis, mutation of these receptor-recycling peroxins 
can result in PEX5 destabilization, as in the pex6-1 mutant [17], or in excessive PEX5 membrane association suggestive of inefficient retrotranslocation, as in the pex4-1 mutant [33] and a pex12 mutant [40]. Moreover, Arabidopsis pex7 mutants display reduced PEX5 levels accompanied by PTS1 import defects in light-grown but not darkgrown seedlings [27]. We used immunoblotting to examine PEX5 levels in our panel of mutants and found that all of the dark-grown mutants except pex6-1 accumulated detectable levels of PEX5 when grown at $22{ }^{\circ} \mathrm{C}$. However, PEX5 levels were clearly reduced following growth in the dark at high temperature in several mutants (Fig. 1b), especially in pex7-2 and in the receptor-recycling mutants (pex4-1, pex2-1, and pex10-2). We confirmed that PEX4 is needed to maintain PEX5 levels at elevated growth temperature by using an intronic pex4 mutant (pex4-2). Although pex4-2 did not display obvious physiological defects (Fig. 2a, b and Additional file 1C), we found similar high temperature-induced PEX5 reduction in both pex4-1 and pex4-2 (Fig. 2c).

\section{Overexpressing PEX5 exacerbates the peroxisomal defects of pex4-1}

Because PEX5 is inefficiently retrotranslocated from the peroxisomal membrane in pex4-1 [33], and because both sucrose dependence and PEX5 levels were reduced in pex4-1 following growth at elevated temperature (Fig. 1a, b), we tested whether overexpressing PEX5 using the constitutive cauliflower mosaic virus (CaMV) 355 promoter might exacerbate pex4-1 defects. Whereas overexpressing PEX5 in wild type did not confer IBA resistance or sucrose dependence in dark-grown seedlings (Fig. 2a, b and Additional file 1C), we found that overexpressing PEX5 increased the IBA resistance (Fig. 2b) and heightened the thiolase PTS2 processing defect (Fig. 2c) of dark-grown pex4-1 seedlings, again suggesting a key role for PEX5 levels or localization in pex4-1 physiological defects. Growth at elevated temperature only partially ameliorated the increased IBA resistance and PTS2 processing defects of pex4-1 35S:PEX5 (Fig. 2b, c) and failed to rescue the sucrose dependence of pex4-1 35S:PEX5 (Fig. 2a). In contrast, overexpressing PEX7, the PTS2 matrix protein receptor, did not worsen pex4-1 defects but rather appeared to rescue the mild thiolase PTS2-processing defect of pex4-1 at $22{ }^{\circ} \mathrm{C}$ (Fig. 2c). Overexpression of either PEX5 or PEX7 did not markedly alter levels of PEX14 or peroxisomal ascorbate peroxidase (APX3), two peroxisomal membrane proteins (Fig. 2c).

To determine whether PEX5 levels were affected by PEX4 overexpression, we compared PEX5 levels in pex4-1 seedlings transformed with a genomic copy of PEX4 or a PEX4 cDNA driven from the CaMV $35 S$ promoter [13]. As previously shown [13], both constructs fully rescued the sucrose dependence and IBA resistance of dark-grown pex4-1 seedlings (Additional file 2). Moreover, the IBA sensitivity, sucrose independence, and PEX5 levels in these lines also resembled wild type following growth at $28{ }^{\circ} \mathrm{C}$, despite the excess PEX4 that accumulated in the 35S:PEX4 line (Additional file 2). These results suggest that PEX4 is not limiting for PEX5 degradation in wild type.

\section{Physiological and molecular defects of pex4-1 are enhanced by mutations in PEX5}

Because overexpressing PEX5 exacerbated pex4-1 mutant defects and because growth at high temperature ameliorated pex4-1 mutant defects while reducing PEX5 levels, we assessed how reducing PEX5 function through mutation would affect pex4-1 mutant defects. Two Arabidopsis pex5 mutants have been described: the missense pex5-1 allele [3] specifically disrupts PTS2 import [25] whereas the pex5-10 T-DNA insertion allele [13] expresses reduced levels of a truncated PEX5 product and disrupts both PTS1 and PTS2 import $[27,41]$. We found that the pex4-1 pex5-1 double mutant was more sucrose dependent (Fig. 3a) and IBA resistant (Fig. 3b) than either single mutant and that these defects were not ameliorated by growth at elevated temperature (Fig. 3a, b). Similarly, combining pex4-1 with pex5-10 resulted in seedlings that, like pex5-10, remained fully sucrose dependent (Fig. 3a) and IBA resistant (Fig. 3b) and were more impaired than pex5-10 when grown with sucrose supplementation (Additional file 1D). Moreover, the germination defect of pex5-10 [41] was exacerbated by pex4-1; double mutant seedlings germinated less efficiently than pex5-10 when incubated at $22^{\circ} \mathrm{C}$ and generally failed to germinate when incubated at $28^{\circ} \mathrm{C}$, so we could not assess IBA responsiveness or sucrose dependence of pex4-1 pex5-10 at elevated temperature.

Immunoblotting revealed that growth at high temperature further reduced levels of the truncated pex5-10 protein but seemed to reduce the thiolase PTS2 processing defect in pex5-10 (Fig. 3c). Despite the enhanced physiological defects displayed by the double mutants (Fig. 3a and b), combining pex4-1 with pex5-1 or pex5-10 did not dramatically alter the thiolase PTS2 processing defects (Fig. 3c).

\section{Growth at reduced temperature exacerbates the peroxisomal defects of pex4-1}

Because high temperature alleviated the pex4-1 physiological defects, we tested whether reduced growth temperature would intensify these defects. Although growth at $15{ }^{\circ} \mathrm{C}$ did not appear to enhance the sucrose dependence of pex4-1 (Fig. 4a), we found that pex4-1 seedlings grown at $15{ }^{\circ} \mathrm{C}$ were more IBA resistant than seedlings grown at $22{ }^{\circ} \mathrm{C}$ (Fig. 4b, Additional file 1E) whereas wild-type seedlings displayed robust IBA responsiveness when grown at $15{ }^{\circ} \mathrm{C}$. Similarly, the PTS2 


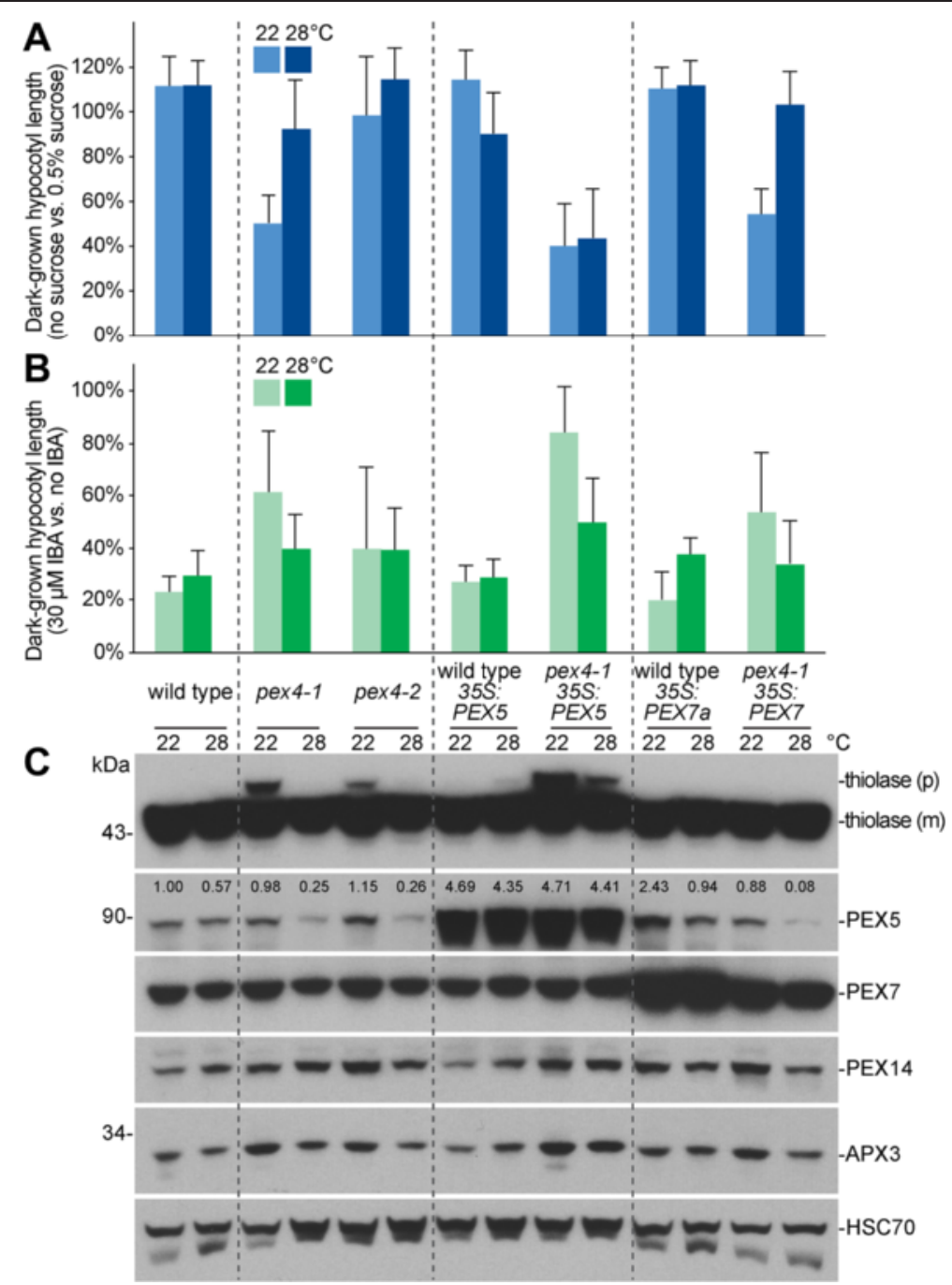

Fig. 2 Overexpressing PEX5 but not PEX7 worsens the peroxisomal defects of pex4-1. a, b Seedlings were grown as in the legend of Fig. 1. Means of normalized dark-grown hypocotyl lengths and standard deviations of the means are shown $(n \geq 18)$. PEX5 was overexpressed in wild type and pex4-1 using the 35S:PEX5 construct [17]. PEX7 was overexpressed in wild type using the 355:PEX7a construct [27] and in pex4-1 using the 35S:PEX7 construct [25]. c Protein extracts of dark-grown seedlings from $0.5 \%$ sucrose-supplemented plant nutrient media were processed for immunoblotting. The membrane was serially probed with the indicated antibodies. Thiolase is synthesized as a PTS2-containing precursor (p) and cleaved in the peroxisome into a mature $(\mathrm{m})$ form. $\mathrm{HSC70}$ was used to monitor protein loading. The positions of molecular mass markers (in $\mathrm{kDa}$ ) are indicated on the left. Band intensities were quantified using ImageJ; levels of PEX5 were normalized to the corresponding HSC70 band prior to normalizing to the $22{ }^{\circ} \mathrm{C}$ wild-type band to give the listed numbers

processing defect of pex4-1 was more apparent following growth at reduced temperature (Fig. 4c). Overexpressing PEX5 exacerbated pex4-1 defects and growing at reduced temperature further worsened the thiolase PTS2 processing defects of pex4-1 (Fig. 4c). Moreover, PEX5 levels, which did not vary markedly in wild-type seedlings grown at different temperatures, showed a clear negative correlation with growth temperature in the pex4-1 mutant, with more PEX5 protein accumulating at cooler temperatures and less PEX5 accumulating at elevated growth temperatures (Fig. 4c).
PEX5 is more membrane associated in pex4-1; high temperature does not rescue this defect

Certain mutants defective in receptor-recycling peroxins, including pex4-1 and pex6-1, display an elevated fraction of membrane-associated PEX5 [33]. We hypothesized that high temperature might increase membrane fluidity and allow more efficient PEX5 retrotranslocation in the pex4-1 mutant, thus explaining the observed physiological rescue. To test this idea, we used cellular fractionation coupled with immunoblotting to monitor PEX5 localization in seedlings grown at 22 or $28{ }^{\circ} \mathrm{C}$. As 


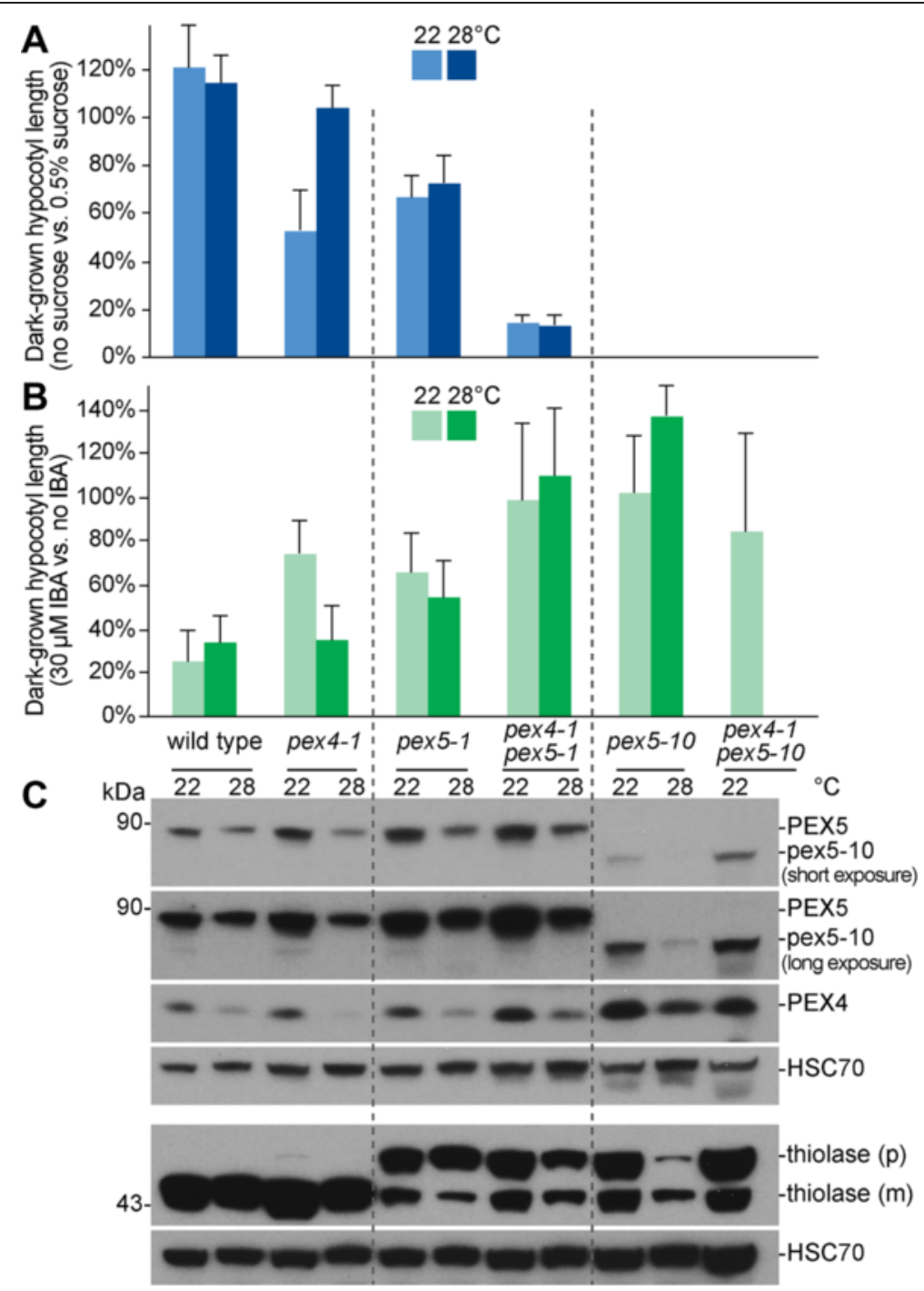

Fig. 3 Peroxisomal defects of pex4-1 are exacerbated by the pex5-1 and pex5-10 mutations. $\mathbf{a}$, b Seedlings were grown as in the legend of Fig. 1. Means of normalized dark-grown hypocotyl lengths and standard deviations of the means are shown ( $n \geq 7$ ). No bars are shown for pex4-1 pex $5-10$ at $28{ }^{\circ} \mathrm{C}$ because of extremely poor germination rate (one seed germinated on $0.5 \%$ sucrose-supplemented plant nutrient medium out of approximately 100 seeds plated; none germinated without sucrose or with $30 \mu \mathrm{M} \mathrm{IBA).} \mathrm{c} \mathrm{Protein} \mathrm{extracts} \mathrm{of} \mathrm{dark-grown} \mathrm{seedlings} \mathrm{from} 0.5 \%$ sucrose-supplemented plant nutrient media were processed for immunoblotting. The membrane was serially probed with the indicated antibodies. Thiolase is synthesized as a PTS2-containing precursor ( $p$ ) and cleaved in the peroxisome into a mature (m) form. HSC70 was used to monitor protein loading. The positions of molecular mass markers (in $\mathrm{kDa}$ ) are indicated on the left

expected, the PEX14 membrane peroxin was fully membrane associated in wild type and pex4-1 at either growth temperature (Fig. 5). As previously observed in light-grown seedlings [33], we found that in extracts from dark-grown wild-type seedlings, PEX5 was mostly soluble following growth at $22{ }^{\circ} \mathrm{C}$ and that pex4-1 had a higher fraction of membrane-associated PEX5 (Fig. 5). We further found that growth at elevated temperature $\left(28{ }^{\circ} \mathrm{C}\right)$ did not notably alter PEX5 membrane association in wild type. Moreover, high temperature did not rescue the high membrane-associated PEX5 defect in pex4-1; rather, the PEX5 pellet/supernatant ratio was elevated further when pex4-1 was grown at high temperature (Fig. 5). We concluded that the physiological rescue observed following growth of pex4-1 at high temperature did not result from restoration of PEX5 retrotranslocation from the peroxisomal membrane.

PEX7 recognizes and delivers PTS2 cargo, but the PEX7 recycling mechanism is not well understood. Unlike PEX5 levels, PEX7 levels (Fig. 2) or membrane association (Fig. 5) did not noticeably change following growth at elevated temperature. 


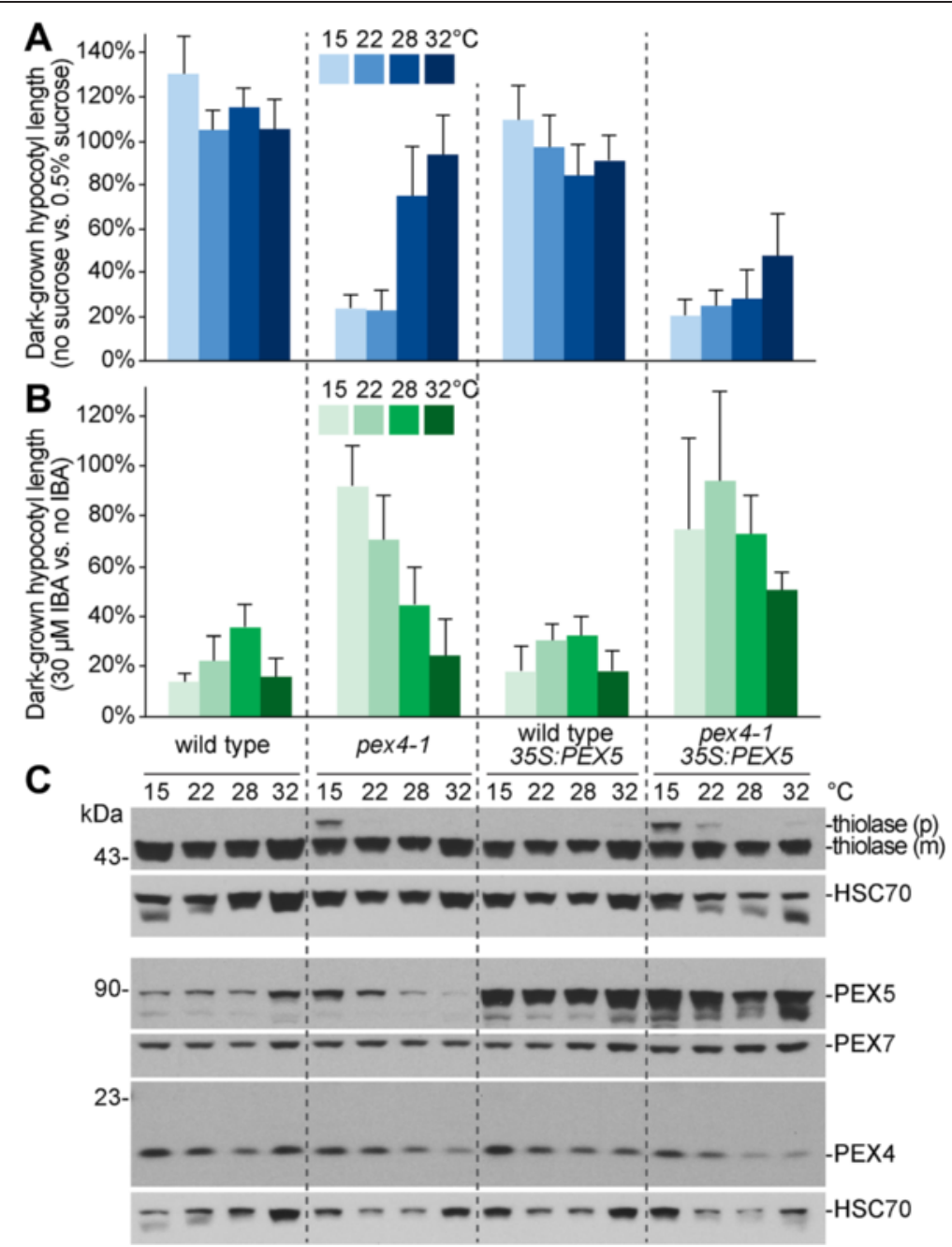

Fig. 4 Low temperature worsens the peroxisomal defects of pex4-1. Seedlings were grown in the dark at $15,22,28$, or $32{ }^{\circ} \mathrm{C}$ with or without $0.5 \%$ sucrose (a) or $30 \mu \mathrm{M}$ IBA (b). Means of normalized dark-grown hypocotyl lengths and standard deviation of the means are shown ( $n \geq 20$ ). c Protein extracts of dark-grown seedlings from $0.5 \%$ sucrose-supplemented plant nutrient media were processed for immunoblotting. The membrane was serially probed with the indicated antibodies. Thiolase is synthesized as a PTS2-containing precursor ( $p$ ) and cleaved in the peroxisome into a mature $(\mathrm{m})$ form. HSC70 was used to monitor protein loading. The positions of molecular mass markers (in kDa) are indicated on the left

\section{High temperature-induced PEX5 reduction in pex4-1 is not due to autophagy}

Because growth at elevated temperature reduced overall PEX5 levels in the pex4-1 mutant, we explored the molecular basis of this reduction. We first tested for the involvement of autophagy in PEX5 degradation. In macroautophagy, an isolation membrane selectively engulfs specific or general cellular components for ultimate degradation in the vacuole [42]. ATG7 is required for lipidation of the ubiquitin-like ATG8 that marks the isolation membrane [42] and is thus required for autophagy of peroxisomes (pexophagy) [43]. We found that preventing autophagy by crossing pex4-1 to the atg7-3 null allele [44] did not increase PEX5 accumulation in pex4-1 at either growth temperature (Fig. 6), suggesting that high temperature-induced PEX5 reduction in pex4-1 does not require autophagy.

\section{MG132 treatment implicates ubiquitin-dependent} proteasomal degradation in regulating PEX5 levels

In yeast, ubiquitinated PEX5 is retrotranslocated from the membrane by the PEX1-PEX6 ATPase complex for recycling, but if this retrotranslocation is slowed, ubiquitination promotes PEX5 degradation by the proteasome [16, 45]. A role for the proteasome in Arabidopsis PEX5 degradation has not been directly demonstrated but is implied by the reduced PEX5 levels found in the Arabidopsis pex6-1 mutant [17]. To test proteasomal involvement in Arabidopsis PEX5 degradation, we used a proteasome inhibitor, MG132, to slow ubiquitin-dependent proteasomal 


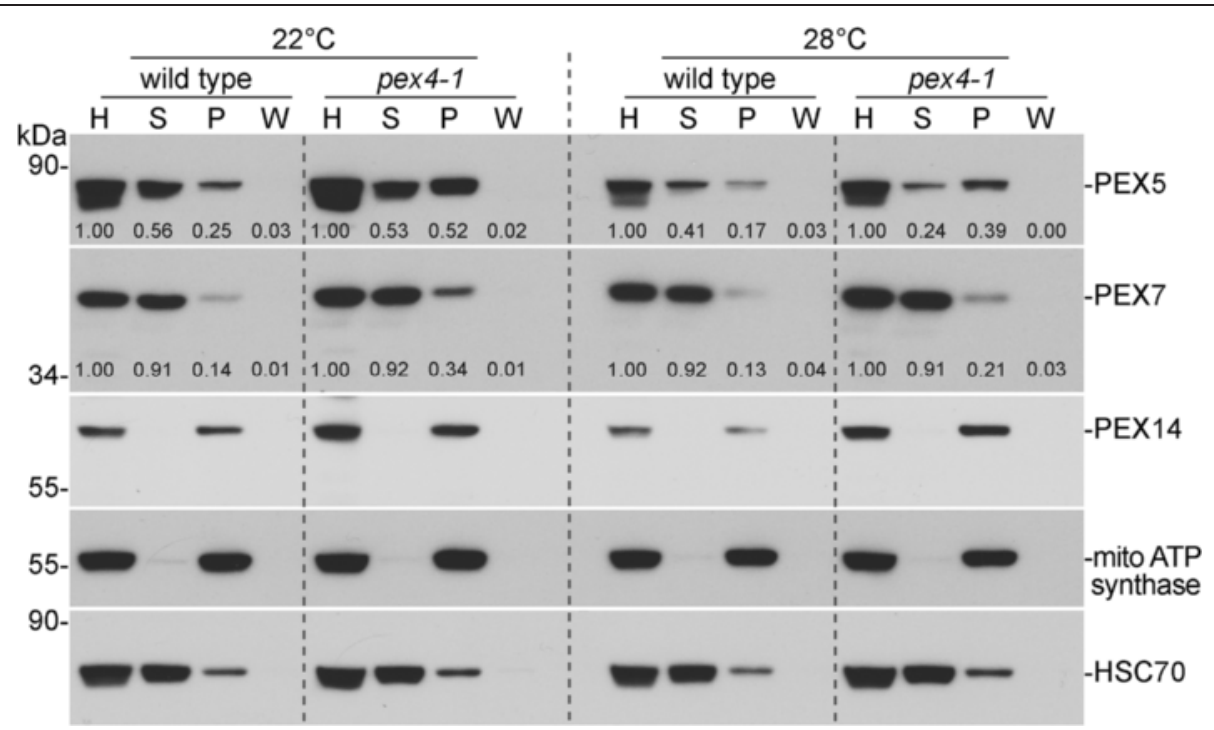

Fig. 5 PEX5 is more membrane associated in pex4-1; high temperature does not rescue this defect. Extracts from dark-grown seedlings grown at $22^{\circ} \mathrm{C}$ or $28^{\circ} \mathrm{C}$ were cleared by a low-speed centrifugation to give homogenates $(\mathrm{H})$. After a high-speed centrifugation, supernatants $(\mathrm{S})$ were removed, and pellets were resuspended and spun at high speed to separate the wash supernatants $(\mathrm{W})$ and final pellets (P). Equal volumes of each fraction were processed for immunoblotting by sequential incubation of the membrane with the indicated antibodies. PEX14 and mitochondrial (mito) ATP synthase are integral membrane proteins; HSC70 is mainly cytosolic. The positions of molecular mass markers (in kDa) are indicated on the left. Band intensities were quantified using ImageJ. For each sample, the supernatant, pellet, and wash were normalized to the corresponding homogenate to give the listed numbers

degradation [46, 47]. We found that PEX5 levels were similarly elevated following a 24-h MG132 treatment at both normal and elevated temperature in wild type (Fig. 7), suggesting that PEX5 can normally be degraded in a proteasome-dependent manner. PEX5 levels in pex4-1 grown at either normal or elevated temperature were also increased by MG132 treatment (Fig. 7),

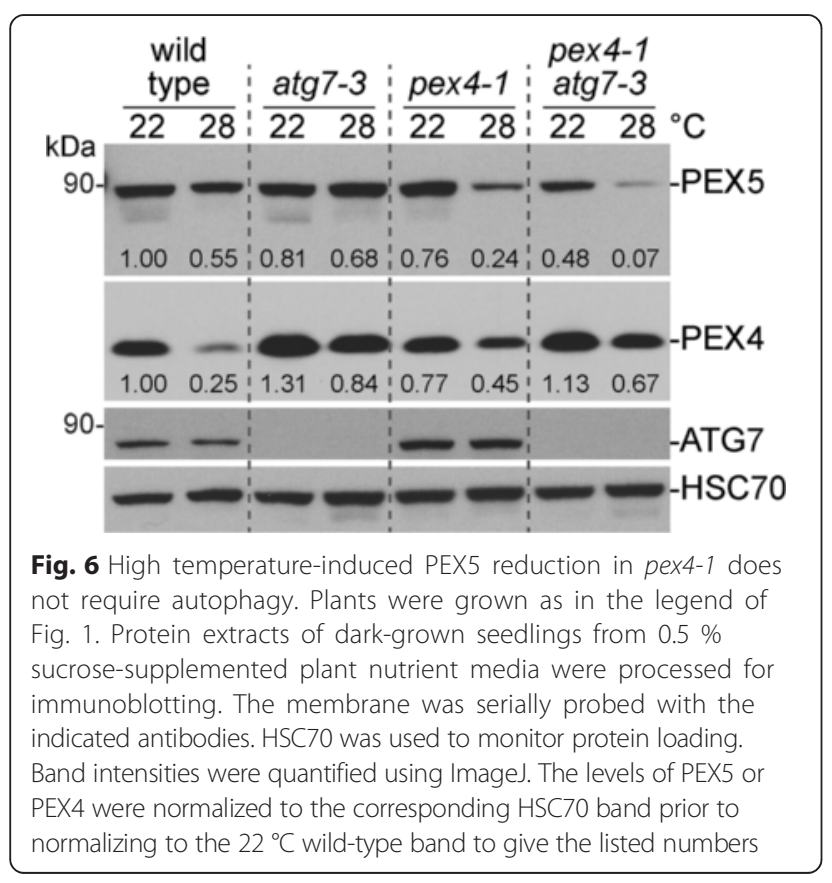

suggesting that the proteasome contributes to PEX5 degradation in pex4-1 as well. Interestingly, the relative increase in PEX5 levels following MG132 treatment was greater in pex4-1 grown at elevated temperature than in wild type, suggesting that PEX5 degradation by the proteasome is enhanced in pex4-1 mutants grown at elevated temperature. In contrast to PEX5 levels, the levels of PEX7 were largely unchanged in this experiment (Fig. 7), demonstrating that not all peroxins were similarly sensitive to MG132 treatment.

We also observed that the PTS2-containing precursor of thiolase accumulated to higher levels in pex4-1 and pex6-1 mutants following MG132 treatment (Fig. 7). This result suggests that mislocalized cytosolic thiolase can be degraded by the proteasome or that the matrix protein import defects of these mutants were worsened by MG132 treatment.

\section{Discussion}

PEX4 is a ubiquitin-conjugating enzyme tethered to the peroxisome by PEX22 [13]. PEX4 is necessary for peroxisomal matrix protein import, probably via its role in ubiquitinating the PEX5 matrix protein receptor, which allows efficient retrotranslocation of PEX5 from the membrane by the PEX1-PEX6 ATPase complex (Fig. 8a) [48]. The Arabidopsis pex4-1 mutant is caused by a Pro123Leu missense mutation and displays a variety of phenotypes suggestive of peroxisome deficiencies, 


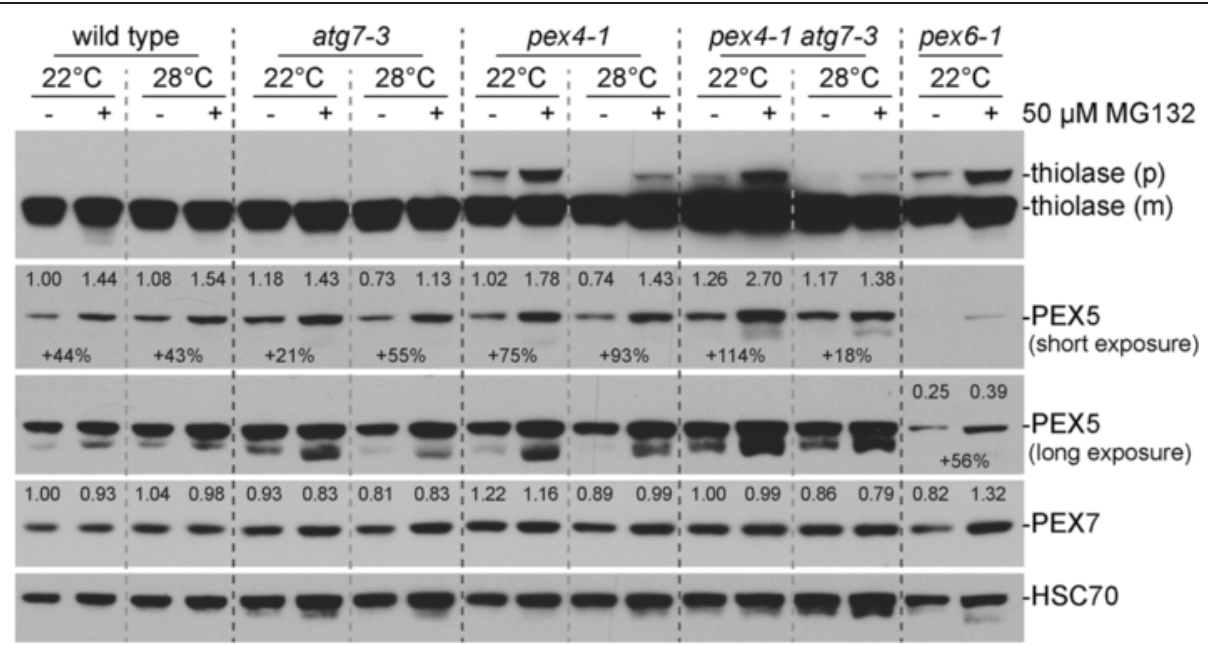

Fig. 7 PEX5 degradation is reduced following treatment with the MG132 proteasome inhibitor. One-day stratification and one-day preincubation were performed prior to plating. Plates were placed in yellow light at $22{ }^{\circ} \mathrm{C}$ for one day and wrapped in aluminum foil at $22{ }^{\circ} \mathrm{C}$ for three days. Seedlings were moved to $0.5 \%$ sucrose-supplemented liquid plant nutrient media with or without $50 \mu \mathrm{M} \mathrm{MG} 132$ in the dark for $24 \mathrm{~h}$ at 22 or $28^{\circ} \mathrm{C}$. Protein extracts of dark-grown seedlings were processed for immunoblotting. The membrane was serially probed with the indicated antibodies. Thiolase is synthesized as a PTS2-containing precursor ( $p$ ) that is cleaved in the peroxisome to the mature (m) form. HSC70 was used to monitor protein loading. Band intensities were quantified using ImageJ. The levels of PEX5 and PEX7 were normalized to the corresponding $\mathrm{HSC70}$ band prior to normalizing to the $22{ }^{\circ} \mathrm{C}$ non-MG132-treated wild-type band to give the listed numbers

including sucrose dependence, IBA resistance, inefficient PTS2 processing [13], PTS1 import defects [14], and elevated membrane-associated PEX5 [33]. Mounting evidence suggests that PEX5 lingering in the membrane is harmful to peroxisome physiology. For example, overexpressing PEX5 confers sucrose dependence and enhances PTS2 processing defects in Arabidopsis pex10-2, a mutant defective in one of the RING-finger peroxins [14]. Furthermore, slightly reducing levels of PEX13, which assists in docking PEX5 at the membrane [35], ameliorates the physiological defects of pex4-1 [33]. In this work, we found that overexpressing PEX5 exacerbated the sucrose dependence, IBA resistance, and PTS2 processing defects of the pex4-1 mutant (Figs. 2 and 4, Additional file 1C, E). These findings are consistent with the hypotheses that the PEX4 ubiquitin-conjugating enzyme normally promotes PEX5 retrotranslocation from the peroxisomal membrane and that PEX5 impairs peroxisome physiology if not promptly removed from the membrane after cargo delivery.

Various environmental stimuli can affect peroxisome numbers and functions in plant cells. For example, cadmium and salinity treatments induce production of reactive nitrogen species in peroxisomes [49-51]. Slightly elevated temperature is associated with increased peroxisome numbers in Norway spruce (Picea abies L. Karst.) [6] and salt $(\mathrm{NaCl})$ stress promotes peroxisome proliferation in Arabidopsis roots [52]. However, the interplay of the environment on peroxisomes in plants with compromised peroxisome function remains largely unexplored. In this study, we found that PEX5 levels are reduced following growth of receptor recycling mutants at elevated temperature (Fig. 1b), suggesting that the activity of the receptor recycling machinery might be temperature-dependent.

We found that growth at elevated temperature rescued the sucrose dependence of dark-grown pex4-1 seedlings (Fig. 1a) and ameliorated the pex4-1 thiolase PTS2processing defect (Figs. 2c and 4c) whereas growth at decreased temperature had opposite effects (Fig. 4). PEX4 levels decreased at high temperature (Figs. 1b, 3, 4c, 6), suggesting that the observed phenotypic rescue was not due to restoration of PEX4 levels in the mutant. Importantly, the elevated ratio of membrane-associated versus cytosolic PEX5 in pex4-1 was not corrected by growth at high temperature (Fig. 5), indicating that high temperature did not restore pex4-1 enzymatic activity or increase membrane fluidity to facilitate PEX5 retrotranslocation. Reduced overall PEX5 levels accompanied the amelioration of pex4-1 physiological defects at high temperature (Figs. 1, 2, 3, 4, 6, 7), further supporting the conclusion that membrane-associated PEX5 impairs peroxisome function in pex4-1. Blocking autophagy did not prevent the high temperature-induced PEX5 reduction in pex4-1 (Fig. 6), suggesting that PEX5 was not degraded by autophagy at high temperature in pex4-1. In contrast, using MG132 to slow ubiquitin-dependent proteasomal degradation restored PEX5 levels in pex4-1 grown at high temperature to wild-type levels (Fig. 7). Interestingly, proteasomal degradation also can contribute to heat stress resistance in rice [53]. Together, our data are consistent with a model in which high temperature promotes 


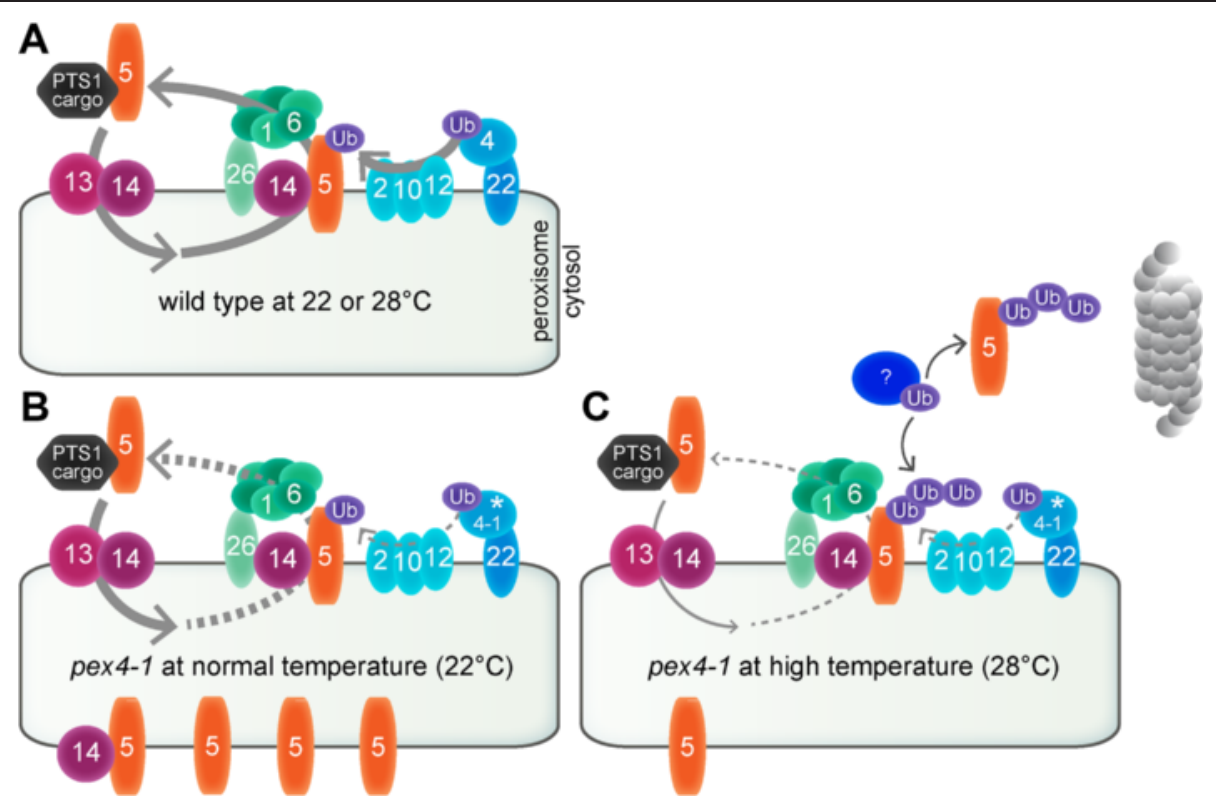

Fig. 8 A working model for high-temperature amelioration of pex4-1 physiological defects. a In wild type, PEX5 recognizes and delivers PTS1 cargo into peroxisomes. The peroxisome-tethered ubiquitin conjugating enzyme (PEX4) and RING finger peroxins (PEX2, PEX10, PEX12) collaborate to ubiquitinate PEX5. Ubiquitinated PEX5 is recycled back to the cytosol by the PEX1-PEX6 ATPase complex. $\mathbf{b}$ At normal growth temperature $\left(22^{\circ} \mathrm{C}\right)$, mutations in PEX4 slow PEX5 recycling, resulting in elevated membrane-associated PEX5, which contributes to pex4 physiological defects. These defects are amplified by PEX5 overexpression, implying that these defects do not exclusively result from reduced matrix protein import. c At high temperature $\left(28^{\circ} \mathrm{C}\right.$ ), an unknown ubiquitination enzyme (question mark) promotes ubiquitin-dependent PEX5 degradation, reducing overall PEX5 levels and ameliorating pex4 defects

ubiquitin-dependent proteasomal degradation of PEX5 in pex4-1, which reduces membrane-associated PEX5 and relieves pex4-1 physiological defects (Fig. 8).

In yeast, the PTS1 cargo receptor PEX5, together with the docking peroxin PEX14, forms transient pores in the peroxisomal membrane to deliver cargo into peroxisomes [11]. PEX4 assists the RING-finger peroxins in ubiquitinating PEX5 [54], allowing PEX5 to be returned to the cytosol and thereby removing the membrane pore. How PEX5 topology changes as it cycles between a soluble protein in the cytosol and an integral protein in the peroxisomal membrane is not known. Moreover, it is not clear why overexpressing PEX5 worsens defects in certain peroxisomal mutants (this study and [14]). We speculate that the excess membrane-associated PEX5 in pex4-1 (this study and [33]) might still be in the pore conformation, altering peroxisome matrix $\mathrm{pH}$, redox status, and/or cofactor availability, thereby disrupting peroxisome metabolism and contributing to the observed physiological defects in pex4-1.

Although high-temperature induced reductions in PEX5 levels were associated with ameliorated pex4-1 peroxisomal defects (Figs. 1, 2, 3, 4), and although PEX5 overexpression (Fig. 2) and low-temperature induced increases in PEX5 levels (Fig. 4) were associated with worsened pex4-1 defects, reducing PEX5 function by mutation did not reduce pex4-1 defects. In fact, the pex4-1 pex5-1 and pex4-1 pex5-10 double mutants displayed exaggerated peroxisome-related physiological defects compared to the parents (Fig. 3a, b). This enhancement suggests that the pex $5-1$ and pex5-10 proteins, which do not efficiently import peroxisomal matrix proteins $[3,27,41]$, confer additional detriment to peroxisome function when not efficiently retrotranslocated (i.e., in a pex4-1 mutant). We expect that a pex 5 mutation that reduces PEX5 protein levels without otherwise impairing PEX5 function might ameliorate the peroxisomal defects of pex4-1, as suggested by the finding that slightly reducing levels of the PEX13 docking peroxin reduces the physiological defects of pex4-1 without notably impairing peroxisome function [33].

Yeast PEX14 is required for pexophagy [55], and yeast mutants lacking PEX4 display elevated PEX14 levels [12], consistent with the possibility that PEX4 might directly or indirectly promote pexophagy as well. In mammalian cells, PEX5 brings the tuberous sclerosis complex to the peroxisome, where it regulates the mTORC pathway and autophagy to suppress tumor formation [56]. The $\operatorname{WXXX}(\mathrm{F} / \mathrm{Y})$ motif in the $\mathrm{N}$-terminal region of PEX5 that binds PEX14 during PTS1 cargo delivery [57-59] is similar to the WXXL ATG8-binding sequence that targets proteins to the autophagy machinery [60]. Although pexophagy recently has been described in Arabidopsis [43, 61, 62], the roles of individual plant 
peroxins in this process have not been reported. We found no evidence that pexophagy was generally induced in pex4-1; levels of the peroxisomal membrane proteins PEX14 and APX3 were not reduced in pex4-1 (Fig. 2c). Interestingly, PEX4 protein was generally less abundant following growth at elevated temperature (Figs. 1b, 3c, 4c, 6 ), and blocking autophagy moderated this decline and partially restored PEX4 levels in pex4-1 (Fig. 6). These results suggest that autophagy might contribute to PEX4 degradation at high temperature.

Human peroxisome biogenesis disorders (PBDs) are genetic diseases caused by peroxin mutations and lack effective treatments. PBD patients have developmental delays and neuropathies that often result in early mortality [63]. Arabidopsis peroxisomal mutants share some molecular phenotypes with fibroblasts from PBD patients. For example, both human cells with mutations in PEX6 [64] and Arabidopsis pex6-1 mutants [17] have low PEX5 levels (e.g., Fig. 1b, 7). Interestingly, low temperature increases membrane-association of PEX5 in normal human cells [64] and increases peroxisomal import in cells from a PBD patient carrying a PEX6 mutation [65]. It is possible that low temperature slows PEX5 degradation and increases PEX5 levels in PEX6-deficient cells. Here, we discovered that growth at high temperature reduced overall PEX5 levels in the Arabidopsis pex4-1 mutant. Together, these results reinforce the idea that therapies targeting PEX5 levels or localization might improve peroxisome functioning in certain PBD patients.

\section{Conclusions}

We propose a model (Fig. 8) in which PEX5 in the pex4-1 mutant lingers on the peroxisomal membrane, which impairs peroxisomal functioning. When pex4-1 seedlings are grown at high temperature, overall PEX5 levels are reduced via an MG132-inhibitable mechanism, presumably proteasomal degradation. This degradation reduces PEX5 accumulation on the peroxisomal membrane. Our results suggest that efficient removal of PEX5 from the peroxisome after cargo delivery is needed not simply to make PEX5 available for further import rounds but also to prevent the peroxisome dysfunction that results from PEX5 lingering in the peroxisomal membrane.

\section{Methods}

\section{Plant materials and growth conditions}

Arabidopsis thaliana wild type and mutants were in Columbia-0 (Col-0) background. atg7-3 [44], pex2-1 [14], pex4-1 [13], pex5-1 [3], pex5-10 [13], pex6-1 [17], pex7-2 [27], pex10-2 [14], pex13-4 [35], pex14-1 [34], Col-0 transformed with 35S:PEX5 [17], Col-0 transformed with 35S:PEX7 [25], Col-0 transformed with 35S:PEX7a [27], and pex4-1 transformed with a genomic rescue construct (PEX4g) or a 35:PEX4 construct (PEX4c)
[13] were previously described. pex4-2 was a gift from Kim Gonzalez and Wendell Fleming.

pex4-1 was crossed to Col-0 transformed with 35S:PEX5 [17] and to Col-0 transformed with 35S:PEX7 [25]. Lines homozygous for pex4-1 and the transgene were selected in progeny of the cross by using PCR-based genotyping (Additional file 3). pex4-1 was crossed to $\operatorname{atg} 7-3$, pex5-1, and pex5-10, and the corresponding double mutants were selected from the progeny of the crosses by using PCRbased genotyping (Additional file 3 and [3, 13, 43]).

Surface-sterilized seeds were grown on plant nutrient medium [66] solidified with $0.6 \%$ (w/v) agar and supplemented with the indicated concentrations of sucrose and/or IBA. The IBA stock solution $(100 \mathrm{mM})$ was dissolved in ethanol. One-day stratification in the dark and one-day preincubation in light were performed prior to plating. Plates were placed in yellow light at $22{ }^{\circ} \mathrm{C}$ for one day and wrapped in aluminum foil at 22 or $28{ }^{\circ} \mathrm{C}$ for four more days, after which dark-grown hypocotyl lengths were measured. For MG132 treatment, plants were grown as described but wrapped in aluminum foil for three days at $22{ }^{\circ} \mathrm{C}$ followed by transfer to $0.5 \%$ sucrose-supplemented liquid plant nutrient media with or without $50 \mu \mathrm{M}$ MG132 for $24 \mathrm{~h}$ in the dark at 22 or $28{ }^{\circ} \mathrm{C}$.

\section{Immunoblotting}

A rabbit antiserum was generated against a peptide from near the C-terminus of PEX4 (C126-N141, CDSGNLLRSGDVRGFN) and affinity purified by Bethyl Laboratories (Montgomery, TX). This antibody recognized an $\sim 18 \mathrm{kDa}$ protein in immunoblots of wild-type seedling extracts that was not detected in pex4-2, which carries an intronic G-to-A mutation 18 base pairs upstream of the fourth exon of PEX4.

Protein extracts from seedlings grown on $0.5 \%$ sucrosesupplemented plant nutrient medium in the dark were processed for immunoblotting. Frozen seedlings were ground with plastic pestles in $1.7 \mathrm{~mL}$ tubes, and two volumes of 2X sample buffer (500 mM Tris pH 8.0, $4 \%(\mathrm{w} / \mathrm{v})$ lithium dodecyl sulfate, $1 \mathrm{mM}$ EDTA, $20 \%$ (w/v) glycerol, $0.44 \mathrm{mM}$ Coomassie blue G250, $0.332 \mathrm{mM}$ phenol red) were added. Supernatants after centrifugation $\left(4{ }^{\circ} \mathrm{C}\right.$, $13200 \mathrm{rpm}, 5 \mathrm{~min}$ ) were transferred to new tubes, and dithiothreitol (DTT) was added to $50 \mu \mathrm{M}$ final concentration. Samples were heated at $95{ }^{\circ} \mathrm{C}$ for five minutes. Equal volumes of samples, Cruz markers (Santa Cruz Biotech, sc-2035), and pre-stained markers (New England Biolabs, P7708S) were loaded onto NuPAGE or Bolt $10 \%$ (w/v) Bis-Tris gels (Invitrogen) and electrophoresed in $50 \mathrm{mM}$ MOPS free acid, $50 \mathrm{mM}$ Tris base, $0.1 \%(\mathrm{w} / \mathrm{v})$ sodium dodecyl sulfate, $1 \mathrm{mM}$ EDTA. Proteins were transferred to Hybond-ECL nitrocellulose membranes (Amersham Hybond ECL, RPN303D) at $24 \mathrm{~V}$ for $45 \mathrm{~min}$ prior to 
blocking in $8 \%$ non-fat dry milk in Tris-buffered saline with Tween-20 (20 mM Tris $\mathrm{pH} 7.5,150 \mathrm{mM} \mathrm{NaCl}$, $0.1 \%(\mathrm{v} / \mathrm{v})$ Tween-20). Membranes were incubated overnight with rabbit primary antibodies diluted in blocking solution that were raised against PEX4 (1:100), PEX5 (1:100, [17]), PEX7 (1:800, [27]), PEX14 (1:10000, Agrisera AS08 372, [67]), thiolase (1:5000, [68]), APX3 $(1: 1000,[69,70])$, or ATG7 (1:1000, [71]) followed by horseradish peroxidase-linked goat anti-rabbit antibody (1:5000, Santa Cruz Biotechnology sc-2030). A mouse primary antibody against HSC70 (1:50000 - 1:100000, Stressgen HPA-817) paired with horseradish peroxidase-linked goat anti-mouse antibody (1:5000, Santa Cruz Biotechnology sc-2031) was used to monitor protein loading, and mitochondrial ATP synthase (1:2000, Abcam \#ab14748, also paired with anti-mouse secondary antibody) was used to validate fractionation experiments. Antibodies were visualized by Western Bright ECL substrate (Advansta K-12045) and exposed on autoradiography film (Genesee 30-810C). Band intensity was analyzed using ImageJ [72].

\section{Fractionation}

Equal weights $(750 \mathrm{mg})$ of 5-day-old dark-grown seedlings were cut with scissors in $1 \mathrm{~mL}$ cold fractionation buffer [150 mM pH7.6 Tris, $100 \mathrm{mM}$ sucrose, $10 \mathrm{mM} \mathrm{KCl}$, $1 \mathrm{mM}$ EDTA, $1 \mathrm{mM}$ DTT, $1 \mathrm{mM}$ phenylmethyl sulfonyl fluoride (from a freshly made stock in isopropanol), 16.7 $\mu \mathrm{L}$ plant protease inhibitor cocktail (Sigma P9599), $1 \mathrm{mM}$ N-ethylmaleimide (from a freshly made stock in ethanol)] on ice for five minutes. The chopped tissue and buffer were transferred to a $1 \mathrm{~mL}$ Dounce homogenizer (VWR 62400-595), homogenized for 20 strokes, and filtered through Miracloth (Calbiochem). Extracts were cleared by a low-speed centrifugation $(50 \mathrm{x} \mathrm{g}, 10 \mathrm{~min})$ to give homogenates $(\mathrm{H})$. After a high-speed centrifugation (15300 x g, $20 \mathrm{~min}$ ), the supernatants (S) were removed. The pellets were resuspended and spun at high speed $(15300 \mathrm{x} \mathrm{g}, 20 \mathrm{~min})$ to separate the wash supernatants (W) and final pellets (P). Corresponding volumes of $4 \mathrm{X}$ loading buffer were added, and equal volumes of each fraction were used for electrophoresis and immunoblotting with the indicated antibodies.

\section{Additional files}

Additional file 1: Dark-grown hypocotyl lengths at different growth temperature. Physiological consequences of growth temperature on wild type and pex mutants (A), wild type and pex4-1 on various auxins (B), overexpressing PEX5 or PEX7 in wild type or pex4-1 (C, E), and pex4-1 pex5 double mutants (D). Seedlings were grown in the dark at indicated temperatures with or without $0.5 \%$ sucrose, $30 \mu \mathrm{M}$ IBA, $1.2 \mu \mathrm{M}$ IAA, $2 \mu \mathrm{M}$ 2,4-DB, or 600 nM 2,4-D. Dark-grown hypocotyl lengths were measured. Means of dark-grown hypocotyl lengths and standard deviations of the means are shown. Normalized data from panels A, B, C, D, and E are presented in Figs. 1a, c-f, 2, 3, and 4, respectively. No bars are shown for pex4-1 pex5-10 at $28^{\circ} \mathrm{C}(\mathrm{D})$ because of the extremely poor germination rate (one seed germinated on $0.5 \%$ sucrose-supplemented plant nutrient medium out of approximately 100 seeds plated; none germinated without sucrose or with $30 \mu \mathrm{M}$ IBA). (PDF $114 \mathrm{~kb}$ )

Additional file 2: Validation of the PEX4 antibody. Seedlings were grown as in the legend of Fig. 1. Means of dark-grown hypocotyl lengths (A), normalized dark-grown hypocotyl lengths $(B, C)$, and standard deviations of the means are shown $(n \geq 18)$. (D) Protein extracts of dark-grown seedlings from $0.5 \%$ sucrose-supplemented medium were processed for immunoblotting. The membrane was serially probed with the indicated antibodies. Thiolase is synthesized as a PTS2-containing precursor $(p)$ and cleaved in the peroxisome into a mature $(m)$ form. HSC70 was used to monitor protein loading. The positions of molecular mass markers (in kDa) are indicated on the left. (PDF $3182 \mathrm{~kb}$ )

Additional file 3: PCR-based markers for genotyping mutants. pex4-1 carries a C-to-T mutation at the $533^{\text {rd }}$ nucleotide that destroys an Mnll restriction enzyme cut site. pex4-2 carries an intronic G-to-A mutation at the $1085^{\text {th }}$ nucleotide (18 bp upstream of the fourth exon of PEX4). We used the dCAPS website (http://helix.wustl.edu/dcaps/dcaps.html, [73]) to design a genotyping marker for pex4-2. pex5-1 carries a C-to-T mutation at the $2910^{\text {th }}$ nucleotide that destroys an EcoRl restriction enzyme cut site [3]. pex5-10 has a T-DNA inserted in exon 5 that results in reduced accumulation of a truncated pex5-10 protein [13]. The 35S:PEX5 construct used a PEX5 CDNA [17]; for 35S:PEX5 genotyping, PEX5 primers spanning introns were used to amplify larger genomic PEX5 or the smaller PEX5 CDNA products. PEX7 lacks introns, so a primer from the 355 promoter and a reverse PEX7 primer were used to genotype PEX7-overexpressing lines. (PDF $71 \mathrm{~kb})$

\section{Abbreviations}

APX: Ascorbate peroxidase; 2,4-D: 2,4-dichlorophenoxyacetic acid; 2,4-DB: 2,4dichlorophenoxybutyric acid; CaMV: Cauliflower mosaic virus;

DTT: Dithiothreitol; IAA: Indole-3-acetic acid; IBA: Indole-3-butyric acid; PBD: Peroxisome biogenesis disorder; PEX: Peroxin; PTS: Peroxisome targeting signal.

\section{Competing interests}

The authors declare that they have no competing interests.

\section{Authors' contributions}

BB and YTK designed the experiments. YTK executed the experiments. $B B$ and YTK wrote the article and approved the final version of the article.

\section{Acknowledgments}

We thank Sarah Ratzel for crossing pex4-1 to 35S:PEX5 and 35S:PEX7 and pex4-1 pex5-1 seeds, Charles Danan for pex4-1 atg7-3 seeds, Kim Gonzalez and Wendell Fleming for pex4-2 seeds, and Bethany Zolman for assistance in generating the PEX4 antibody. We thank Richard Trelease and Richard Vierstra for antibodies recognizing APX3 and ATG7, respectively. We are grateful for critical comments on the manuscript from Wendell Fleming, Kim Gonzalez, Roxanna Llinas, Mauro Rinaldi, Andrew Woodward, Zachary Wright, and Pierce Young. This research was supported by the NIH (R01GM079177) and the Robert A. Welch Foundation (C-1309). YTK was supported in part by the Studying Abroad Scholarship from the Ministry of Education, Taiwan.

Received: 10 May 2015 Accepted: 6 September 2015

Published online: 16 September 2015

\section{References}

1. Theodoulou FL, Eastmond PJ. Seed storage oil catabolism: a story of give and take. Curr Opin Plant Biol. 2012;15:322-8.

2. Hayashi M, Toriyama K, Kondo M, Nishimura M. 2,4-Dichlorophenoxybutyric acid-resistant mutants of Arabidopsis have defects in glyoxysomal fatty acid beta-oxidation. Plant Cell. 1998;10:183-95.

3. Zolman BK, Yoder A, Bartel B. Genetic analysis of indole-3-butyric acid responses in Arabidopsis thaliana reveals four mutant classes. Genetics. 2000;156:1323-37.

4. Hu J, Baker A, Bartel B, Linka N, Mullen RT, Reumann S, et al. Plant peroxisomes: biogenesis and function. Plant Cell. 2012;24:2279-303.

5. Smith JJ, Aitchison JD. Peroxisomes take shape. Nat Rev Mol Cell Biol. 2013;14:803-17. 
6. Kivimaenpaa M, Riikonen J, Sutinen S, Holopainen T. Cell structural changes in the mesophyll of Norway spruce needles by elevated ozone and elevated temperature in open-field exposure during cold acclimation. Tree Physiol. 2014;34:389-403.

7. Mullen RT, Flynn CR, Trelease RN. How are peroxisomes formed? The role of the endoplasmic reticulum and peroxins. Trends Plant Sci. 2001;6:256-61.

8. McNew JA, Goodman JM. An oligomeric protein is imported into peroxisomes in vivo. J Cell Biol. 1994;127:1245-57.

9. Chowdhary G, Kataya AR, Lingner T, Reumann S. Non-canonical peroxisome targeting signals: identification of novel PTS1 tripeptides and characterization of enhancer elements by computational permutation analysis. BMC Plant Biol. 2012;12:142.

10. Walton PA, Hill PE, Subramani S. Import of stably folded proteins into peroxisomes. Mol Biol Cell. 1995;6:675-83.

11. Meinecke M, Cizmowski C, Schliebs W, Kruger V, Beck S, Wagner R, et al. The peroxisomal importomer constitutes a large and highly dynamic pore. Nat Cell Biol. 2010;12:273-7.

12. van der Klei IJ, Hilbrands RE, Kiel JA, Rasmussen SW, Cregg JM, Veenhuis M. The ubiquitin-conjugating enzyme Pex4p of Hansenula polymorpha is required for efficient functioning of the PTS1 import machinery. EMBO J. 1998:17:3608-18.

13. Zolman BK, Monroe-Augustus M, Silva ID, Bartel B. Identification and functional characterization of Arabidopsis PEROXIN4 and the interacting protein PEROXIN22. Plant Cell. 2005;17:3422-35.

14. Burkhart SE, Kao YT, Bartel B. Peroxisomal ubiquitin-protein ligases Peroxin2 and Peroxin 10 have distinct but synergistic roles in matrix protein import and Peroxin5 retrotranslocation in Arabidopsis. Plant Physiol. 2014;166:1329-44.

15. Platta HW, Magraoui FE, Baumer BE, Schlee D, Girzalsky W, Erdmann R. Pex2 and Pex12 function as protein-ubiquitin ligases in peroxisomal protein import. Mol Cell Biol. 2009;29:5505-16

16. Thoms S, Erdmann R. Peroxisomal matrix protein receptor ubiquitination and recycling. Biochim Biophys Acta. 2006;1763:1620-8.

17. Zolman BK, Bartel B. An Arabidopsis indole-3-butyric acid-response mutant defective in PEROXIN6, an apparent ATPase implicated in peroxisomal function. Proc Natl Acad Sci USA. 2004;101:1786-91.

18. Platta HW, Grunau S, Rosenkranz K, Girzalsky W, Erdmann R. Functional role of the AAA peroxins in dislocation of the cycling PTS1 receptor back to the cytosol. Nat Cell Biol. 2005;7:817-22.

19. Goto S, Mano S, Nakamori C, Nishimura M. Arabidopsis ABERRANT PEROXISOME MORPHOLOGY9 is a peroxin that recruits the PEX1-PEX6 complex to peroxisomes. Plant Cell. 2011;23:1573-87.

20. Fujiki Y, Miyata N, Matsumoto N, Tamura S. Dynamic and functional assembly of the AAA peroxins, Pex1p and Pex6p, and their membrane receptor Pex26p involved in shuttling of the PTS1 receptor Pex $5 p$ in peroxisome biogenesis. Biochem Soc Trans. 2008;36:109-13.

21. Nashiro C, Kashiwagi A, Matsuzaki T, Tamura S, Fujiki Y. Recruiting mechanism of the AAA peroxins, Pex1p and Pex6p, to Pex26p on the peroxisomal membrane. Traffic. 2011;12:774-88.

22. Gurvitz A, Langer S, Piskacek M, Hamilton B, Ruis H, Hartig A. Predicting the function and subcellular location of Caenorhabditis elegans proteins similar to Saccharomyces cerevisiae ß-oxidation enzymes. Yeast. 2000;17:188-200.

23. Motley AM, Hettema EH, Ketting R, Plasterk R, Tabak HF. Caenorhabditis elegans has a single pathway to target matrix proteins to peroxisomes. EMBO Rep. 2000;1:40-6.

24. Faust JE, Verma A, Peng C, McNew JA. An inventory of peroxisomal proteins and pathways in Drosophila melanogaster. Traffic. 2012;13:1378-92.

25. Woodward AW, Bartel B. The Arabidopsis peroxisomal targeting signal type 2 receptor $\mathrm{PEX7}$ is necessary for peroxisome function and dependent on PEX5. Mol Biol Cell. 2005;16:573-83.

26. Lazarow PB. The import receptor Pex7p and the PTS2 targeting sequence. Biochim Biophys Acta. 2006;1763:1599-604.

27. Ramón NM, Bartel B. Interdependence of the peroxisome-targeting receptors in Arabidopsis thaliana: PEX7 facilitates PEX5 accumulation and import of PTS1 cargo into peroxisomes. Mol Biol Cell. 2010;21:1263-71.

28. Hayashi M, Yagi M, Nito K, Kamada T, Nishimura M. Differential contribution of two peroxisomal protein receptors to the maintenance of peroxisomal functions in Arabidopsis. J Biol Chem. 2005;280:14829-35.

29. Kunze M, Malkani N, Maurer-Stroh S, Wiesinger C, Schmid JA, Berger J. Mechanistic insights into PTS2-mediated peroxisomal protein import: the co-receptor PEX5L drastically increases the interaction strength between the cargo protein and the receptor PEX7. J Biol Chem. 2014;290:4928-40.
30. Helm M, Luck C, Prestele J, Hierl G, Huesgen PF, Frohlich T, et al. Dual specificities of the glyoxysomal/peroxisomal processing protease Deg15 in higher plants. Proc Natl Acad Sci USA. 2007;104:11501-6.

31. Schuhmann H, Huesgen PF, Gietl C, Adamska I. The DEG15 serine protease cleaves peroxisomal targeting signal 2-containing proteins in Arabidopsis. Plant Physiol. 2008;148:1847-56.

32. Miyauchi-Nanri Y, Mukai S, Kuroda K, Fujiki Y. CUL4A-DDB1-Rbx1 E3 ligase controls the quality of the PTS2 receptor Pex7p. Biochemical J. 2014;463:65-74.

33. Ratzel SE, Lingard MJ, Woodward AW, Bartel B. Reducing PEX13 expression ameliorates physiological defects of late-acting peroxin mutants. Traffic. 2011;12:121-34.

34. Monroe-Augustus M, Ramon NM, Ratzel SE, Lingard MJ, Christensen SE,

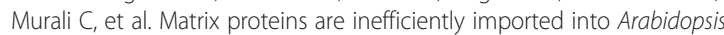
peroxisomes lacking the receptor-docking peroxin PEX14. Plant Mol Biol. 2011;77:1-15.

35. Woodward AW, Fleming WA, Burkhart SE, Ratzel SE, Bjornson M, Bartel B. A viable Arabidopsis pex 13 missense allele confers severe peroxisomal defects and decreases PEX5 association with peroxisomes. Plant Mol Biol. 2014;86:201-14.

36. Strader LC, Culler AH, Cohen JD, Bartel B. Conversion of endogenous indole-3-butyric acid to indole-3-acetic acid drives cell expansion in Arabidopsis seedlings. Plant Physiol. 2010;153:1577-86.

37. Strader LC, Bartel B. Transport and metabolism of the endogenous auxin precursor indole-3-butyric acid. Mol Plant. 2011;4:477-86.

38. Strader LC, Wheeler DL, Christensen SE, Berens JC, Cohen JD, Rampey RA, et al. Multiple facets of Arabidopsis seedling development require indole-3butyric acid-derived auxin. Plant Cell. 2011;23:984-99.

39. Collins CS, Kalish JE, Morrell JC, McCaffery JM, Gould SJ. The peroxisome biogenesis factors Pex4p, Pex22p, Pex1p, and Pex6p act in the terminal steps of peroxisomal matrix protein import. Mol Cell Biol. 2000;20:7516-26.

40. Mano S, Nakamori C, Nito K, Kondo M, Nishimura M. The Arabidopsis pex 12 and pex 13 mutants are defective in both PTS1- and PTS2-dependent protein transport to peroxisomes. Plant J. 2006;47:604-18.

41. Khan BR, Zolman BK. pex5 mutants that differentially disrupt PTS1 and PTS2 peroxisomal matrix protein import in Arabidopsis. Plant Physiol. 2010;154:1602-15.

42. Li F, Vierstra RD. Autophagy: a multifaceted intracellular system for bulk and selective recycling. Trends Plant Sci. 2012;17:526-37.

43. Farmer LM, Rinaldi MA, Young PG, Danan CH, Burkhart SE, Bartel B. Disrupting autophagy restores peroxisome function to an Arabidopsis lon2 mutant and reveals a role for the LON2 peroxisomal protease in matrix protein degradation. Plant Cell. 2013;25:4085-100.

44. Lai Z, Wang F, Zheng Z, Fan B, Chen Z. A critical role of autophagy in plant resistance to necrotrophic fungal pathogens. Plant J. 2011;66:953-68.

45. Kragt A, Voorn-Brouwer T, van den Berg M, Distel B. The Saccharomyces cerevisiae peroxisomal import receptor Pex $5 p$ is monoubiquitinated in wild type cells. J Biol Chem. 2005;280:7867-74.

46. Yang P, Fu H, Walker J, Papa CM, Smalle J, Ju YM, et al. Purification of the Arabidopsis $26 \mathrm{~S}$ proteasome: biochemical and molecular analyses revealed the presence of multiple isoforms. J Biol Chem. 2004;279:6401-13.

47. Genschik P, Criqui MC, Parmentier Y, Derevier A, Fleck J. Cell cycle -dependent proteolysis in plants. Identification of the destruction box pathway and metaphase arrest produced by the proteasome inhibitor MG132. Plant Cell. 1998;10:2063-76.

48. Platta HW, El Magraoui F, Schlee D, Grunau S, Girzalsky W, Erdmann R. Ubiquitination of the peroxisomal import receptor Pex $5 p$ is required for its recycling. J Cell Biol. 2007;177:197-204.

49. Corpas FJ, Barroso JB, Carreras A, Quiros M, Leon AM, Romero-Puertas MC, et al. Cellular and subcellular localization of endogenous nitric oxide in young and senescent pea plants. Plant Physiol. 2004;136:2722-33.

50. Corpas FJ, Hayashi M, Mano S, Nishimura M, Barroso JB. Peroxisomes are required for in vivo nitric oxide accumulation in the cytosol following salinity stress of Arabidopsis plants. Plant Physiol. 2009;151:2083-94.

51. Corpas FJ, Barroso JB. Peroxynitrite (ONOO-) is endogenously produced in Arabidopsis peroxisomes and is overproduced under cadmium stress. Ann Bot. 2014;113:87-96.

52. Mitsuya S, El-Shami M, Sparkes IA, Charlton WL, Lousa Cde M, Johnson B, et al. Salt stress causes peroxisome proliferation, but inducing peroxisome proliferation does not improve $\mathrm{NaCl}$ tolerance in Arabidopsis thaliana. PLoS One. 2010;5:e9408 
53. Li XM, Chao DY, Wu Y, Huang X, Chen K, Cui LG, et al. Natural alleles of a proteasome alpha2 subunit gene contribute to thermotolerance and adaptation of African rice. Nat Genet. 2015;47:827-33.

54. Platta HW, Hagen S, Reidick C, Erdmann R. The peroxisomal receptor dislocation pathway: to the exportomer and beyond. Biochimie. 2014;98:16-28.

55. Zutphen T, Veenhuis $M$, van der Klei IJ. Pex14 is the sole component of the peroxisomal translocon that is required for pexophagy. Autophagy. 2008:4:63-6.

56. Zhang J, Kim J, Alexander A, Cai S, Tripathi DN, Dere R, et al. A tuberous sclerosis complex signalling node at the peroxisome regulates $\mathrm{MTORC} 1$ and autophagy in response to ROS. Nat Cell Biol. 2013;15:1186-96.

57. Natsuyama R, Okumoto K, Fujiki Y. Pex5p stabilizes Pex14p: a study using a newly isolated pex5 CHO cell mutant, ZPEG101. Biochemical J. 2013;449:195-207.

58. Lanyon-Hogg T, Hooper J, Gunn S, Warriner SL, Baker A. PEX14 binding to Arabidopsis PEX5 has differential effects on PTS1 and PTS2 cargo occupancy of the receptor. FEBS Lett. 2014;588:2223-9.

59. Neuhaus A, Kooshapur H, Wolf J, Meyer NH, Madl T, Saidowsky J, et al. A novel Pex14 protein-interacting site of human Pex5 is critical for matrix protein import into peroxisomes. J Biol Chem. 2014;289:437-48.

60. Noda NN, Ohsumi Y, Inagaki F. Atg8-family interacting motif crucial for selective autophagy. FEBS Lett. 2010;584:1379-85.

61. Kim J, Lee H, Lee HN, Kim SH, Shin KD, Chung T. Autophagy-related proteins are required for degradation of peroxisomes in Arabidopsis hypocotyls during seedling growth. Plant Cell. 2013;25:4956-66.

62. Shibata M, Oikawa K, Yoshimoto K, Kondo M, Mano S, Yamada K, et al. Highly oxidized peroxisomes are selectively degraded via autophagy in Arabidopsis. Plant Cell. 2013;25:4967-83.

63. Braverman NE, D'Agostino MD, Maclean GE. Peroxisome biogenesis disorders: biological, clinical and pathophysiological perspectives. Dev Disabil Res Rev. 2013;17:187-96.

64. Dodt G, Gould SJ. Multiple PEX genes are required for proper subcellular distribution and stability of Pex5p, the PTS1 receptor: evidence that PTS1 protein import is mediated by a cycling receptor. J Cell Biol. 1996;135:1763-74.

65. Imamura A, Shimozawa N, Suzuki Y, Zhang Z, Tsukamoto T, Fujiki Y, et al. Temperature-sensitive mutation of PEX6 in peroxisome biogenesis disorders in complementation group C (CG-C): comparative study of PEX6 and PEX1. Pediatr Res. 2000;48:541-5.

66. Haughn GW, Somerville C. Sulfonylurea-resistant mutants of Arabidopsis thaliana. Mol Gen Genet. 1986;204:430-4.

67. Burkhart SE, Lingard MJ, Bartel B. Genetic dissection of peroxisomeassociated matrix protein degradation in Arabidopsis thaliana. Genetics. 2013;193:125-41.

68. Lingard MJ, Monroe-Augustus M, Bartel B. Peroxisome-associated matrix protein degradation in Arabidopsis. Proc Natl Acad Sci USA. 2009;106:4561-6.

69. Corpas FJ, Bunkelmann J, Trelease RN. Identification and immunochemical characterization of a family of peroxisome membrane proteins (PMPs) in oilseed glyoxysomes. Eur J Cell Biol. 1994:65:280-90.

70. Lisenbee CS, Heinze M, Trelease RN. Peroxisomal ascorbate peroxidase resides within a subdomain of rough endoplasmic reticulum in wild-type Arabidopsis cells. Plant Physiol. 2003;132:870-82.

71. Doelling JH, Walker JM, Friedman EM, Thompson AR, Vierstra RD. The APG8/ 12-activating enzyme APG7 is required for proper nutrient recycling and senescence in Arabidopsis thaliana. J Biol Chem. 2002;277:33105-14.

72. Schneider CA, Rasband WS, Eliceiri KW. NIH Image to ImageJ: 25 years of image analysis. Nat methods. 2012;9:671-5.

73. Neff MM, Turk E, Kalishman M. Web-based primer design for single nucleotide polymorphism analysis. Trends Genet. 2002;18:613-5.

\section{Submit your next manuscript to BioMed Central and take full advantage of:}

- Convenient online submission

- Thorough peer review

- No space constraints or color figure charges

- Immediate publication on acceptance

- Inclusion in PubMed, CAS, Scopus and Google Scholar

- Research which is freely available for redistribution

Submit your manuscript at www.biomedcentral.com/submit 